University of Wollongong

Research Online

Faculty of Engineering and Information

Faculty of Engineering and Information

Sciences - Papers: Part A

Sciences

$1-1-2015$

Excellent melt lubrication of alkali metal polyphosphate glass for high temperature applications

\author{
A Kiet Tieu \\ University of Wollongong, ktieu@uow.edu.au \\ Shanhong Wan \\ University of Wollongong, shanhong@uow.edu.au \\ Ning Kong \\ University of Wollongong, nk974@uowmail.edu.au \\ Qiang Zhu \\ University of Wollongong, qiangz@uow.edu.au \\ Hongtao Zhu \\ University of Wollongong, hongtao@uow.edu.au
}

Follow this and additional works at: https://ro.uow.edu.au/eispapers

Part of the Engineering Commons, and the Science and Technology Studies Commons 


\title{
Excellent melt lubrication of alkali metal polyphosphate glass for high temperature applications
}

\author{
Abstract \\ A new class of high temperature lubricant of inorganic alkali metal polyphosphate was developed for hot \\ metal forming, which involved a fundamental knowledge of melt lubrication. At elevated temperature a \\ $55 \%$ reduction in friction and a $50 \%$ decrease in wear were achieved by the presence of the molten \\ polyphosphate lubrication, as well as the excellent anti-oxidation capability at the rubbing steel/steel \\ interface, which closely correlated with the tribo-induced hierarchical structure at the rubbing interface. \\ This inorganic polyphosphate lubricant can be called a smart polymeric material, which will be an eco- \\ friendly alternative for high temperature applications. This journal is

\section{Keywords} \\ melt, high, excellent, glass, polyphosphate, metal, alkali, lubrication, applications, temperature

\section{Disciplines} \\ Engineering | Science and Technology Studies

\section{Publication Details} \\ Tieu, A. Kiet., Wan, S., Kong, N., Zhu, Q. \& Zhu, H. (2015). Excellent melt lubrication of alkali metal \\ polyphosphate glass for high temperature applications. RSC Advances: an international journal to further \\ the chemical sciences, 5 (3), 1796-1800.
}




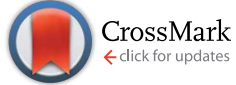

Cite this: RSC Adv., 2015, 5, 1796

Received 9th October 2014 Accepted 26th November 2014

DOI: $10.1039 / c 4 r a 12028 k$

www.rsc.org/advances

\section{Excellent melt lubrication of alkali metal polyphosphate glass for high temperature applications}

\author{
Anh Kiet Tieu, Shanhong Wan, Ning Kong, Qiang Zhu and Hongtao Zhu
}

A new class of high temperature lubricant of inorganic alkali metal polyphosphate was developed for hot metal forming, which involved a fundamental knowledge of melt lubrication. At elevated temperature a $55 \%$ reduction in friction and a $50 \%$ decrease in wear were achieved by the presence of the molten polyphosphate lubrication, as well as the excellent anti-oxidation capability at the rubbing steel/steel interface, which closely correlated with the tribo-induced hierarchical structure at the rubbing interface. This inorganic polyphosphate lubricant can be called a smart polymeric material, which will be an eco-friendly alternative for high temperature applications.

Aerospace systems, advanced combustion engines, mining and metalworking processes often require the use of elevated temperature, in which the mechanical systems are prone to excessive friction and wear as well as serious oxidation of the active surface exposed to oxygen and water, causing premature failure of the machines and an undesirable finish to the products. ${ }^{1}$ Especially hot metal forming, termed as the process of plastically deforming raw steel into a desirable product form, often involves such aggressive conditions, i.e. a $\alpha-\gamma$ transformation temperature around $880{ }^{\circ} \mathrm{C}$ and high pressures. ${ }^{2-4} \mathrm{~A}$ variety of water- and oil-based lubricants have been widely applied to separate the rubbing members by a film of solid or liquid, and to produce less secondary oxide scaling by a lower temperature as a result of heat dissipation by water or oils. ${ }^{5-7}$ However, it is uncertain if a uniform and stable tribofilm can be spontaneously formed on the rubbing members to simultaneously obtain reduced friction and reduced wear, resistance to oxidation corrosion, i.e. oils and greases can rapidly decompose at around $300{ }^{\circ} \mathrm{C}$. Therefore, a new lubricant should be capable of withstanding compression and high temperature in the fluids, and can provide the required set of properties for rubbing systems.

It is well-known that a glass-like polyphosphate boundary film attached to the rubbing surface is considered to be the key

Faculty of Engineering and Information Sciences, University of Wollongong, Wollongong, NSW 2500, Australia. E-mail: ktieu@uow.edu.au; Tel: +61 242213061 for preventing further wear or scuffing at the mixed to boundary lubrication regimes, in the presence of phosphorus-based additives, e.g. ZDDP. ${ }^{8-11}$ Remarkably, this tribofilm shows an excellent adaptive tribology behaviour, which is intelligently responsive to the tribo-stressed conditioins. ${ }^{\mathbf{1 0 , 1 1}}$ Moreover, it can protect the substrate against further oxidation. Alkali metal phosphates glasses, a class of thermoplastic polymers similar to epoxy resin based thermoset, ${ }^{12,13}$ have been implemented in the formulation of ceramic restorative cements and more generally of bioactive functional materials, employed as active elements in laser engineering owing to itself useful optical properties, ${ }^{14-17}$ owing to its exceptionally thermal stability and inability to oxidize, as well as high coefficient of thermal expansion. In particular, above the melting temperature they melt without decomposing, generating the highly viscous melts inclined to promote the adhesion between the lubricant-metal interface, which can bring up exciting possibilities in developing a new class of environmentfriendly lubricating medium for the effective operation of the mechanical systems at high temperatures. Although polyphosphate glasses have been well documented in the molten state, there remains a lack of a tribology of their melts for the high temperature applications. ${ }^{\mathbf{1 8 , 1 9}}$ Insight into the regularities of wear and friction of molten polyphosphate at the rubbing interface is very critical to understand the action mechanism of polyphosphate lubricant at elevated temperatures, however, is still a challenging and fertile area from the microscopic view.

Specifically, this work aims to the introduction of a "green" lubricant of water-soluble polyphosphate polymer for the rubbing surfaces at high temperatures. We hypothesized that the melt of inorganic polyphosphate enables strong boundary film formation for the rubbing steel contact, and displays significant friction-reducing and anti-wear properties at high temperatures. Meanwhile concept of an in situ anti-oxidation design is proposed by the infusion of phosphate species into the underlying surface under dynamic pressures. Furthermore, tribological surface/interface is tailored to allow us to understand the mechanism of lubrication and anti-wear of polyphosphate lubricants. 
In this study, the friction and wear resistance of the steel/ steel contact was determined by a ball-on-disk tribometer to under the unlubricated and lubricated condition, respectively, where the lubricant is sodium polyphosphate and monopotassium phosphate in water. The testing conditions were as follows: an applied load of $10 \mathrm{~N}$ equal to $1.37 \mathrm{GPa}$ of the maximum Hertz contact stresses, a linear velocity of $0.1 \mathrm{~m} \mathrm{~s}^{-1}$, and the temperature of $800{ }^{\circ} \mathrm{C}$. Fig. 1 shows the coefficient of friction as a function of the sliding time under lubricated and unlubricated conditions. Generally, the oxide scales on the steel surface not only provide a good resistance to galling but also act as lubricant to some extent, however, the excessive abrasion of the oxide particles makes it impossible to achieve a stable low friction interface, ${ }^{20,21}$ as a consequence a high coefficient of friction at the rubbing steel/steel contact can be seen about 0.42 shown in Fig. 1a. When the inorganic polyphosphate lubricant presents, the coefficient of friction stabilizes quickly at 0.19 within less than $60 \mathrm{~s}$ shown in Fig. 1a. It is noted that, the friction is substantially reduced by up to $60 \%$ as compared to that under unlubricated condition, which is due to the presence of a viscoelastic film of the molten polyphosphate at the boundary lubrication regime. ${ }^{\mathbf{1 0 , 1 4}}$ Fig. $1 \mathrm{~b}$ demonstrates the presence of polyphosphate lubricant rendering an impressive reduction of wear in the rubbing steel/steel contacts, more than $50 \%$ as compared to that under unlubricated condition. On the one hand, without lubrication the wear loss of the steel disk is $1.91 \mathrm{~mm}^{3}$, while the steel disk has a wear loss of $0.65 \mathrm{~mm}^{3}$ under lubricated condition. On the other hand, the steel ball has a wear loss of around $0.26 \mathrm{~mm}^{3}$ in dry condition, and 0.14 $\mathrm{mm}^{3}$ in presence of phosphate lubrication, respectively. The presence of this molten polyphosphate boundary film is a contributory factor to the improved wear resistant capability of the rubbing steel/steel contacts. As Wang et al. reported that, the strong particle-matrix bonding for epoxy/silica nanocomposites effectively contributes to itself increase in hardness and modulus. ${ }^{15,16}$ In this work alkali metal polyphosphate lubricant is highly reactive, can chemically digest abrasive nanoparticles of iron oxide like ZDDP, forming iron phosphate compounds in polyphosphate matrix by the replacement of $\mathrm{P}-\mathrm{O}-\mathrm{P}$ by $\mathrm{P}-\mathrm{O}-\mathrm{Fe}$ bonds, which gets alkali metal polyphosphate tribofilm acquired higher stiff and strength and therefore higher load-carrying capacity of the anti-wear boundary film. ${ }^{22}$

In addition, serious oxidation of steel surface often occurs at high temperature, and the difference in hardness and ductility of steel and its oxide leads to serious thermal cracks of various kinds, and even oxide peeling off. ${ }^{23,24}$ In this study, after a test at $800{ }^{\circ} \mathrm{C}$ the delamination of superficial oxide scale by the side of the wear track can be clearly observed in Fig. 2a. By contrast, there is no oxide peeling off by the appearance of phosphate lubricant, and this black film well adheres onto the steel surface shown in Fig. 2b. Since polyphosphate lubricant itself has the good oxidation-resistant property, the melting phosphate species will uniformly cover the steel surface, and also react with the metal surface forming phosphate compound film. Thus this film plays a role of the protective barrier to the oxygen diffusion required for oxidation. ${ }^{17}$

It is accepted that the essence of the anti-wear efficiency from phosphorus-based additives closely correlates with the polyphosphate glass film formed on the rubbing metal surfaces, thereby protecting them from wear especially at the mixed to boundary lubrication regime. ${ }^{\mathbf{1 0 , 1 1}}$ Especially polyphosphate tribofilms show the adaptive tribological behaviour in response to different extreme range of conditions, i.e. high loads, high speeds and temperatures, which is primarily related to the preferential alignment of the tribofilm in structure and composition: a layered structure with a gradient composition from surface to the depth..$^{25,26}$ In this study, similar but perhaps more distinctive difference is that potassium and sodium phosphate chemicals are directly introduced into the rubbing steel/steel pair at $800{ }^{\circ} \mathrm{C}$, a remarkable capacity for reducing friction and minimizing wear loss of the rubbing steel/steel pair can be achieved shown in Fig. 2, thanks to the presence of the molten inorganic polyphosphate lubrication film. Therefore, the presence of such alkali metal polyphosphate not only

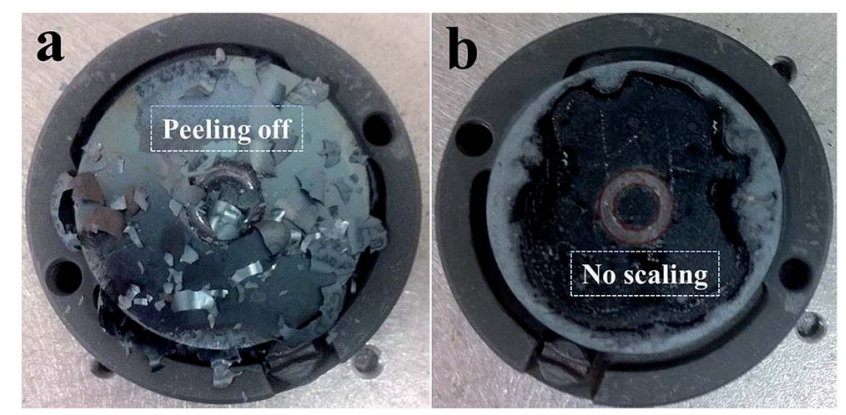

Fig. 2 Surface morphologies of steel disk after the friction tests under unlubricated (a) and lubricated condition (b).
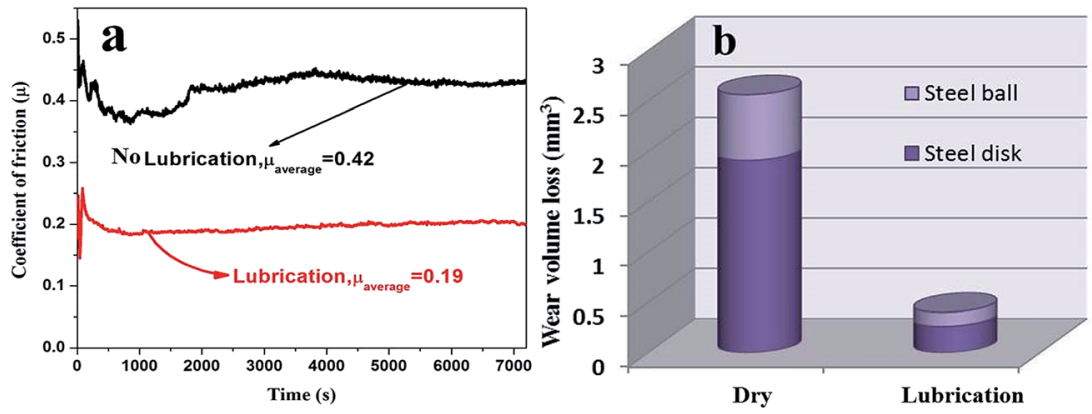

Fig. 1 Friction characteristics (a) and wear loss (b) of steel/steel pair under unlubricated and lubricated conditions at $800{ }^{\circ} \mathrm{C}$. 
facilitates reduction of friction and wear, and also provides an excellent anti-oxidation behaviour, shown in Fig. 1 and 2 . Nevertheless, little is known about the mechanism of such melting polyphosphate lubricant providing its tribological and anti-oxidation synergistic behaviours at elevated temperatures.

In order to elucidate the action mechanism of polyphosphate lubricant at rubbing steel/steel contacts at $800{ }^{\circ} \mathrm{C}$, an observation of this lubricant by the laser scanning confocal microscope confirms the phosphate chemicals at the rubbing surfaces are in the melting state in Fig. 3a, where it shows a uniform melting film spreading on the steel surface with certain flow features similar to those of fluids. ${ }^{7}$ As reported, alkali metal salts have the positive effect on the improvement in the high temperature anti-oxidation stability of lubricant additives. ${ }^{27}$ This result directly shows that, such melting phosphate film provides not only the viscous lubrication but also the good oxidation-resistance as assumed. Moreover, alkali metal polyphosphate compounds have a highly chemical affinity to the metal surface, this fully ensure a good adherence of the melting lubrication film to the steel surface. ${ }^{17}$ Fig. $3 \mathrm{~b}$ presents SEM image of the wear track of the steel disc under lubricated condition, owing to the surface tension the molten polyphosphate film will agglomerate during the post-cooling process, and finally forms streaks spreading out the wear track. ${ }^{23,24}$ And the corresponding EDS analysis well confirms that, in the wear track the streaks consist of $\mathrm{P}, \mathrm{O}, \mathrm{Na}$, and $\mathrm{K}$ elements in Fig. 3c. Because the melting point of sodium polyphosphate and monopotassium phosphate is $616{ }^{\circ} \mathrm{C}$ and $252.6{ }^{\circ} \mathrm{C}$, respectively, the phosphate species definitely melt at $800{ }^{\circ} \mathrm{C}$. Therefore, on the one hand, the molten polyphosphate has the liquid-like lubricating capability, greatly reducing the friction at the rubbing steel/steel contacts by the viscous

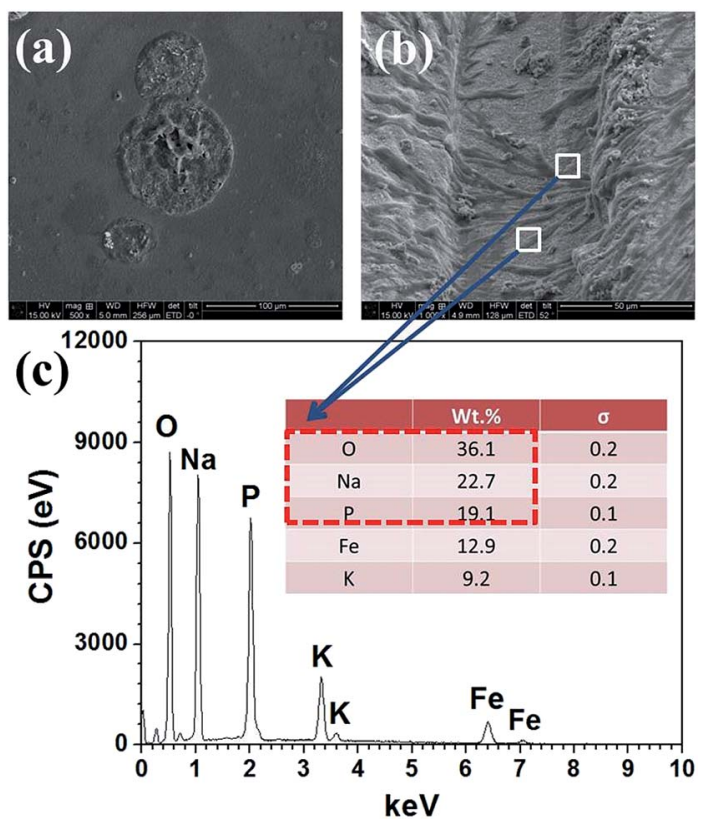

Fig. 3 (a) Scanning electron micrograph (SEM) of polyphosphate lubricant at $800{ }^{\circ} \mathrm{C}$; (b) SEM image of wear track, and (c) the corresponding EDS spectra in the wear tracks. lubrication film..$^{28,29}$ On the other hand, an acid-base reaction occurs between alkali metal polyphosphate and iron oxide nanoscales forming the polyphosphate tribofilm along the rubbing steel surface, this tribofilm have "smart materials behaviour", thus enhancing anti-wear ability to a certain extent. ${ }^{10}$ In addition, polyphosphates of alkaline metals preferentially bonds with the iron/iron oxide surface enables a good adherence of this tribofilm, and this melting film plays the role of the barrier to further oxidize. ${ }^{29}$

The tribological response of polyphosphate lubricant at steel/steel contacts is closely related with the chemical and structure of tribo-surface/interface. Here a near surface of the hierarchical structure can be seen by the bright scanning electron (BSE) image of the cross section in the wear track shown in Fig. 4a, approximately $2 \mu \mathrm{m}$ deep for the worn steel disc obtained. Furthermore, the chemical and structure of this hierarchy tribo-interface can be clearly distinguished by the FIB thinned TEM cross-section of the worn steel disc and its corresponding EDS mapping shown in Fig. $4 \mathrm{~b}$ and c. After the wear test there is a film located on the wear surface of the region (I), it is about $120 \mathrm{~nm}$ thick and mainly consists of alkali metal phosphate of the lubricant, such as $\mathrm{K}, \mathrm{Na}$, and $\mathrm{P}$ elements, acting as the tribo-boundary film responsible for the friction reduction and anti-wear. ${ }^{27}$ Within the subsurface area of region (II), a degree of the plastic deformation can be observed. This layer is mainly iron oxide having a thickness of $1 \mu \mathrm{m}$, which can effectively relieve the local stress concentration during frictional process through the micro cracks or pores associated within them. ${ }^{30}$ Most interestingly, between the oxide scales of region II and the steel oxide base of region IV, an intermediate is mainly made up of phosphate species like $\mathrm{K}, \mathrm{Na}$ and $\mathrm{P}$, though those elements have low contents, they can be tracked across the oxide film of the region (III), thus this region can be called the

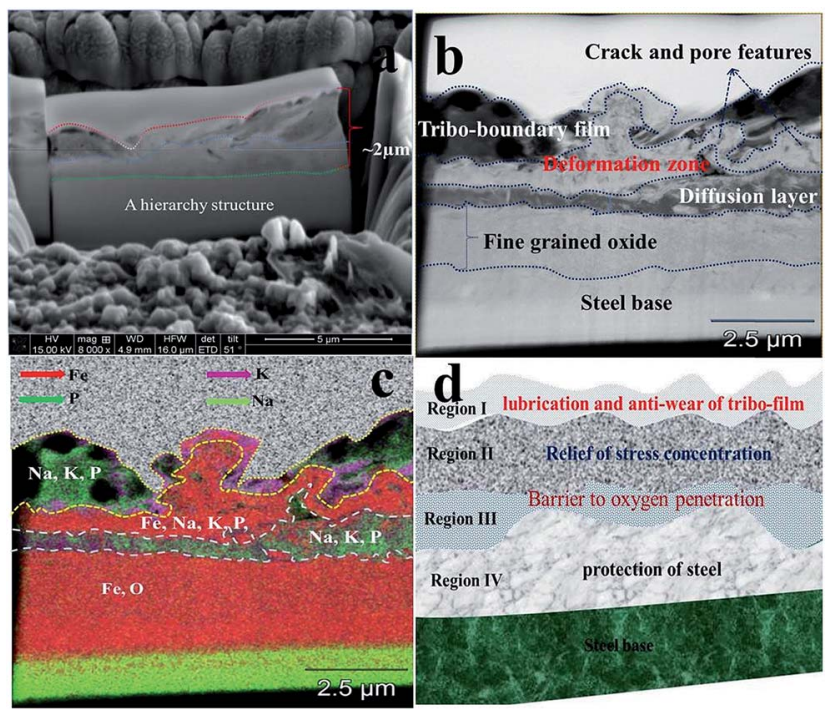

Fig. 4 (a) BSE image of a FIB milled section from the worn surface of steel disk, parallel to the sliding direction, (b) TEM imaging and (c) EDS element mapping in the cross-section of the worn surface of steel disk, (d) a schematic of the frictional-induced hierarchical structure of the worn steel disk and their functions. 
diffusion layer. However, the single thermal test of this lubricant onto steel surface shows no such region in the underlying surface. It can be concluded that the phosphate fluids penetrate into the interface between the loose and compact oxides under the tribo-stressed condition and act as a binder, turning the oxide scales a compact solid to a certain degree. ${ }^{31}$ Therefore, such a phosphate subscale in region (III) can well restrict free access of oxygen to the underlying surface and reduce secondary oxide scaling, providing the in situ anti-oxidation capability, this constitutes the third function of this polyphosphate lubricant. Finally, there is the fine grained iron oxide of region IV on the steel base. Therefore, a particular integrated function of the hierarchical structure is obtained including the anti-wear, friction reduction and oxidation resistance, thanks to the presence of the molten inorganic phosphate under the tribo-stressed conditions, and thus it can be inferred to have smart materials behaviour. Accordingly, a schematic of the tribo-induced hierarchical structure of the cross-sectional interface and their respective functions is proposed in Fig. $4 \mathrm{~d}$.

Besides the physical and chemical properties of the mating materials, surface lubrication is influenced mainly by the rheological properties of the lubricating fluid especially the viscosity. ${ }^{32}$ For instance, the decreasing viscosity of the fluid results in decreasing coefficient of friction at rubbing surface, the thicker lubricant fluid film leads to better lubrication. In this study, primary sodium polyphosphate of the lubricant will melt and simultaneously polymerize, and has a low viscosity of around 8 poises at $600{ }^{\circ} \mathrm{C}$ and above. ${ }^{33}$ Therefore polyphosphate melt can lubricate freely rubbing parts at elevated temperatures. However, the investigations of rheological properties of the lubricant should be further carried out to elucidate the effect of temperature and shear rates on viscosity, to further establish the relation between the rheology of the melts and theirs tribological response especially for hot metal forming process.

In summary, this class of inorganic polyphosphate watersoluble lubricant has a technological significance in hot metal machining industry, because this melt can simultaneously provide an exceptionally low coefficient of friction, good antiwear ability of tool and workpiece, and an excellent oxidation inhibition, due to the versatile but integrated functions of the friction-induced hierarchal structure. The lubricant has the potential to improve tribological and anti-oxidation synergistic behaviours of the rubbing members at high temperature applications.

\section{Acknowledgements}

This research used equipment funded by the Australian Research Council (ARC) - JEOL JEM-ARM200F (\#LE120100104) located at the UOW Electron Microscopy Centre.

\section{Notes and references}

1 R. K. Duggan, Y. Y. Tse and M. Z. Quadir, Mater. Manuf. Processes, 2011, 26, 51-57.
2 K. Hara, H. Utsunomiya, R. Matsumoto and T. Sakai, J. Phys., 2012, 379, 012043-012408.

3 J. Hardell, L. Pelcastre and B. Prakash, J. Eng. Tribol., 2010, 224, 1139-1151.

4 H. Karbasian and A. E. Tekkaya, J. Mater. Process. Technol., 2010, 210, 2103-2118.

5 S. Plaza, L. Margielewski, G. Cielichowski, R. W. Wesolowski and R. Stanecka, Wear, 2001, 249, 1077-1089.

6 Z. Pawlak, B. E. Klamecki, T. Rauckyte, G. P. Shpenkov and A. Kopkowski, Tribol. Int., 2005, 38, 1-4.

7 N. Bay, A. Azushima, P. Groche, I. Ishibashi, M. Merklein, M. Morishita, T. Nakamura, S. Schmid and M. Yoshida, CIRP Annals-Manufac. Technol, 2010, 59, 760-780.

8 J. P. Ye, M. Kano and Y. Yasuda, J. Appl. Phys., 2003, 93, 51135117.

9 L. Haack and S. Simko, Surf. Sci. Spectra, 2011, 18, 1-8.

10 D. Shakhvorostov, M. H. Muser, Y. Song and P. R. Norton, J. Chem. Phys., 2009, 131, 044704-044708.

11 D. Shakhvorostov, M. H. Muser, N. J. Mosey, Y. Song and P. R. Norton, Phys. Rev. B: Condens. Matter Mater. Phys, 2009, 79, 094107(9).

12 Z. Z. Wang, P. Gu, Z. Zhang, L. Gu and Y. Z. Xu, Tribol. Lett., 2011, 42, 185-191.

13 Z. Z. Wang, P. Gu, X. P. Wu, H. Zhang, Z. Zhang and M. Y. M. Chiang, Compos. Sci. Technol., 2013, 79, 49-57.

14 S. Shahrbar, R. V. Noort, B. Mirzakouchaki, E. Ghassemieh and N. Martin, Dent. Mater., 2014, 30, 234-241.

15 E. A. A. Neel, D. M. Pickup, S. P. Valappil, R. J. Newport and J. C. Knowles, J. Mater. Chem., 2009, 19, 690-701.

16 E. L. Falcão Filho, C. A. C. Bosco, G. S. Maciel, B. de Araújo Cid, M. Nalin and Y. Messaddeq, Appl. Phys. Lett., 2003, 83, 1292-1294.

17 T. K. Pavlushkina and I. V. Morozova, Glass Ceram, 2011, 67, 312-315.

18 A. V. Khomenko and I. A. Lyashenko, Phys. Lett. A, 2007, 366, 165-173.

19 I. A. Lyashenko, A. V. Khomenko and L. S. Metlov, Tech. Phys., 2010, 55, 1193-1199.

20 M. Pellizzari, D. Cescato and M. G. Flora, Wear, 2009, 267, 467-475.

21 A. Caron, P. Sharma, A. Shluger, H.-J. Fecht, D. V. LouzguineLuzguin and A. Inoue, J. Appl. Phys., 2011, 109, 083515(7).

22 Z. Pawlak, P. K. D. V. Yarlagadda, R. Frost and D. Hargreaves, JAMME, 2009, 37, 458-465.

23 O. Barrau, C. Boher, R. Gras and F. Rezai-Aria, Wear, 2003, 255, 1444-1454.

24 I. Sallit, C. Richard, G. Bèranger, D. Kircher and H. Michaud, Tribol. Lett., 2002, 12, 147-154.

25 F. Gao, O. Furlong, P. V. Kotvis and W. T. Tysoe, Langmuir, 2004, 20, 7557-7568.

26 M. A. Nicholls, T. Do, P. R. Norton, M. Kasrai and G. M. Bancroft, Tribol. Int., 2005, 38, 15-39.

27 J. Yao and J. Dong, Tribol. Trans., 1996, 39, 498-505.

28 I. A. Lyashenko, Tech. Phys., 2011, 56, 869-876.

29 I. A. Lyashenko, Tech. Phys., 2012, 57, 17-26.

30 J. Qu, D. G. Bansal, B. Yu, J. Y. Howe, J. Y. Howe, H. M. Luo, S. Dai, H. Q. Li, P. J. Blau, B. G. Bunting, G. Mordukhovich 
and D. J. Smolenski, ACS Appl. Mater. Interfaces, 2012, 4, 9971002.

31 F. T. Lv, L. G. Wang and E. Z. Wang, Adv. Mater. Res., 2013, 821/822, 1256-1260.
32 Y. Z. Hu and S. Granick, Tribol. Lett., 1998, 5, 81-88.

33 E. J. Griffith and C. F. Callis, J. Am. Chem. Soc., 1959, 81, 833836. 